\title{
DESENVOLVIMENTO DE INDICADORES DE
}

\section{SuStentabILIDADE PARA A GESTÃo dE UM CAMPUS}

\section{e-Xactal}

\author{
UNIVERSITÁRIO UTILIZANDO O BALANCED SCORECARD
}

ISSN: 1984-3151

\author{
DEVELOPMENT OF SUSTAINABILITY'S INDICATORS TO THE \\ MANAGEMENT OF a CAMPUS USING THE BSC
}

Mariana Pereira Carneiro'; Fernanda dos Santos Silva²; Brenda de Farias Oliveira
Cardoso $^{3}$; Verônica de Menezes Nascimento Nagata ${ }^{4}$, Léony Luis Lopes Negrão

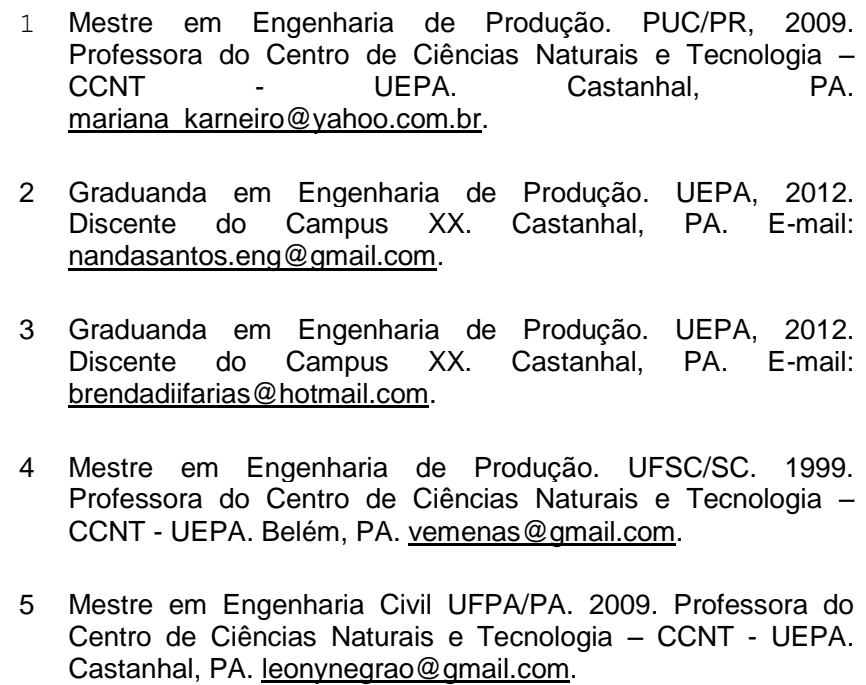

Recebido em: 04/04/2016 - Aprovado em: 04/11/2016 - Disponibilizado em: 30/11/2016

RESUMO: Os indicadores de desempenho simbolizam o desempenho das organizações no mercado em que estão inseridas. Mesmo sendo mais constantes em empresas privadas, nas organizações públicas e sem fins lucrativos, a possibilidade de a ferramenta melhorar a administração é reconhecida em perspectivas econômica, social e ambiental. Assim, o trabalho objetivou a criação de indicadores de sustentabilidade utilizando o Balanced Scorecard em um campus universitário, definindo quais medidas, métricas e iniciativas devem ser seguidas para implementar sua estratégia. Desse modo, por meio do planejamento, observações e análise dos ambientes, foi possível criar uma matriz SWOT, para auxiliar na definição dos objetivos do campus; um mapa estratégico, para comunicar os objetivos; e um plano de ação, para a implementação da estratégia. Além disso, os resultados obtidos mostraram a relevância dos métodos de gestão para empresas públicas, além de contribuir com o conhecimento acerca de indicadores de sustentabilidade em universidades.

PALAVRAS-CHAVE: Medição de desempenho. Indicadores de sustentabilidade. Balanced Scorecard. Universidade pública.

ABSTRACT: Performance indicators symbolize the performance of organizations in the market that they are inserted. Even being more constants in private companies, the ability of the tool to improve the administration in public and non-profit organizations is recognized in economic, social and environmental perspectives. Therefore, this paper aimed the creation of sustainability indicators using Balanced Scorecard on a university campus, defining which measures metrics and initiatives must be pursued to implement its strategy. Thus, after planning, observing and analyzing the environment, it was possible to create a SWOT matrix to assist the definition of the campus goals, a 
strategic map to communicate the goals and an action planning to implement the strategy. Besides, the results show the importance of management methods for public companies, in addition to contributing to the knowledge of sustainability indicators in universities.

Keywords: Performance measurement. Sustainability indicators. Balanced scorecard. Public university.

\section{INTRODUÇÃo}

Para atender às exigências de mercado e, principalmente, dos clientes, as organizações estão cada vez mais adequando seu modelo de gestão estratégica e operacional. O modelo contábil, que antigamente era eficiente em ambientes regidos por controle de estoque e processos de produção, atualmente não garante a estabilidade da empresa que, necessita de meios para ser competitiva na era da informação (SILVA, 2003).

Os indicadores financeiros não sinalizavam o desempenho organizacional das empresas. Desse modo, gestores foram compelidos a buscar meios que aumentassem sua capacidade de gestão não financeira, como indicadores referentes a clientes, participação no mercado, capacidade de inovação, além da responsabilidade social e ambiental (SILVA, 2003).

Mesmo sendo uma realidade inerente a empresas privadas, as organizações sem fins lucrativos, em especial as públicas, precisam também agregar um pouco desta perspectiva. Poister, Aristigueta e Hall (2015) colocam que planejamento estratégico, gestão por desempenho e um forte foco na abordagem baseada em mercado são componentes relevantes para uma moderna gestão pública.

Tais organizações apresentam constantes desafios de gestão, onde os gastos são limitados às rubricas orçamentárias e, muitas vezes, os recursos financeiros são escassos. Essa situação leva a decisões mais assertivas, de maneira que saibam onde e como aplicar suas disponibilidades financeiras baseando-se em suas prioridades.
Ainda que não precisem gerar lucro, as organizações do terceiro setor demandam, cada vez mais, uma gestão profissionalizada, que Ihes permita avaliar adequadamente a utilização dos recursos aplicados no alcance de sua missão de forma sustentável. Especialmente porque esses recursos são, na maioria das vezes, oriundos de doações ou de receitas públicas (VIANNA; ENSSLIN, 2007).

Bititci et al. (2012) apontam que a medição de desempenho no setor público é uma das áreas que merece ser melhor explorada em pesquisas, onde se investiga como o conhecimento pode ser utilizado para gerar sistemas de medição de desempenho em organizações sem fins lucrativos. Por isso, há a necessidade de maiores estudos nessa área.

Nesse contexto, está inserido o Balanced Scorecard (BSC), que, segundo Hubbard (2009) é modelo gerencial de desempenho de auxílio ao planejamento estratégico, que busca definir indicadores por meio das suas perspectivas (financeira, do cliente, dos processos internos e aprendizado e crescimento). O autor ainda afirma que os indicadores direcionam qual o melhor posicionamento a ser tomado pela empresa, mostrando seus resultados e, também, seu desempenho.

Apesar do BSC ser concebido para organizações lucrativas, geralmente privadas, a possibilidade de a ferramenta melhorar a administração em empresas públicas e instituições sem fins lucrativos é reconhecida numa perspectiva econômica e financeira (KAPLAN; NORTON, 1997).

Aliado ao BSC, a sustentabilidade representa uma temática relevante para qualquer tipo de organização. Nos últimos tempos, houve um aumento exponencial 
em referências e estudos sobre sustentabilidade e estratégias para alcançar desenvolvimento sustentável, onde é quase impossível que empresas não apresentem qualquer preocupação com o tema (MONTIEL; DELGADO-CEBALLOS, 2014).

O conceito de Elkington (2001) mostra que a sustentabilidade é vista por meio de três dimensões: econômica, social e ambiental. Tendo em vista o contexto de que as instituições governamentais, em sua essência, possuem o foco de atuação voltado para a sociedade, englobar aspectos sobre a sustentabilidade se torna essencial para 0 desenvolvimento da presente pesquisa.

A partir dessa motivação, o referido trabalho tem como objetivo desenvolver indicadores de desempenho com foco na sustentabilidade em um campus de uma universidade pública no interior do Estado do Pará. Para isso, utilizou-se o BSC como base para a criação de um mapa estratégico e um plano de ação para o campus, definindo os indicadores e a estratégia a ser seguida.

O presente trabalho está organizado de acordo com as seguintes seções: a primeira trata dos aspectos introdutórios da pesquisa, apresentando motivações e o objetivo geral; enquanto que a segunda seção traz o referencial teórico utilizado para embasar o desenvolvimento da pesquisa; já a terceira seção traz os procedimentos metodológicos adotados; a quarta seção traz os resultados e; a quinta e última aponta os aspectos de conclusão e sugestão de futuros trabalhos.

\section{REFERENCIAL TEÓRICO}

Nessa seção, abordam-se os conceitos e teorias utilizadas para o embasamento do desenvolvimento da pesquisa em questão, acerca sustentabilidade, medição de desempenho e Balanced Scorecard, a partir de referências consolidadas.

\subsection{SUSTENTABILIDADE}

O conceito de sustentabilidade foi proposto pela Comissão Brundtland em 1987, um grupo denominado pelas Nações Unidas para propor estratégias de melhoria do bem-estar da humanidade sem ameaçar o ambiente e assim, surgiu o famoso relatório Brundtland onde o grupo divulgou o conceito de desenvolvimento sustentável (BLACKBURN, 2007), que é $O$ desenvolvimento que preenche as necessidades do presente, sem comprometer a habilidade das gerações futuras de preencherem suas próprias necessidades" (COMISSÃO MUNDIAL SOBRE MEIO AMBIENTE E DESENVOLVIMENTO, 1991).

O desenvolvimento sustentável surgiu quando se percebeu que o uso sem restrições dos recursos naturais para obter crescimento econômico poderia ser prejudicial ao futuro da sociedade. Por isso, as organizações buscam o equilíbrio entre o que é socialmente desejável, economicamente justo e ecologicamente sustentável, o que é considerado o tripé da sustentabilidade. (TREVISAN et al. apud OLIVEIRA et al., 2012).

O primeiro pilar é o da sustentabilidade econômica, que faz menção aos resultados econômico-financeiros da empresa, abordando os conceitos de custo e resultados operacionais e dados contábeis (ELKINGTON, 2001).

Os outros dois pilares são um pouco mais difíceis de compreender a sua extensão, que são os pilares ambiental e social. O pilar ambiental trata da utilização dos recursos naturais (energia, terra, água) nas operações e sobre 0 que os produtos geram (desperdícios, emissão de gases, resíduos químicos) (HUBBARD, 2009). Já a sustentabilidade social trata das questões relacionadas ao capital social: como a empresa considera a saúde, habilidades e educação. Está bastante ligada à satisfação dos stakeholders e 
no impacto social das atividades da empresa junto a eles (ELKINGTON, 2001).

Assim, para Dyllick e Hockerts (2002), ter sustentabilidade organizacional significa atender às necessidades dos stakeholders diretos e indiretos, sem comprometer as necessidades dos destes no futuro e para isso é preciso se manter e crescer em termos econômicos, sociais e ambientais.

\subsection{Medição de Desempenho e BSC}

No que tange à medição de desempenho três conceitos são básicos: medição de desempenho, indicadores ou medidas de desempenho e sistemas de medição de desempenho.

Para Neely, Gregory e Platts (1995), a medição de desempenho consiste em quantificar a eficiência e eficácia de um processo.

Lebas (1995) difere medição de desempenho de gestão por desempenho, onde a primeira definição trata de definição e descrição de medidas de desempenho, enquanto a segunda trata de como a organização gerencia o desempenho da organização, envolvendo questões de treinamento, diálogo, sistemas de comunicação, estilo de gestão.

Quanto à definição de indicadores ou medidas de desempenho, Neely, Gregory e Platts (1995) afirma que pode ser definida como uma métrica para quantificar a eficiência e eficácia de um processo.

Os sistemas de medição de desempenho, de acordo com Neely, Gregory e Platts (1995) correspondem ao conjunto de métricas utilizadas para medir a eficiência e eficácia de um processo.

Martins (1999) explica que por meio do sistema de medição de desempenho é possível melhorar a gestão do desempenho, visto que, os dados de uma empresa convertidos em informações relevantes influenciam na tomada de decisões de uma organização, e assim, possibilita escolhas melhores para obter melhores resultados.

Para Martins (1999) e Bititci (2015), antes dos anos de 1980 , os sistemas de medição de desempenho eram baseados em medidas financeiras, preocupados com a vertente econômica da empresa, pois avaliavam apenas o desempenho dos gerentes e ignorando outros stakeholders.

Com a mudança do modelo de organização contextual, onde a gestão estratégica e a busca e maior necessidade de colaboração interorganizacional, tais medidas de desempenho tornaram-se insuficientes (BITITCI, 2015). Portanto, faziam-se necessários medidores que avaliassem os outros pontos relevantes (MARTINS, 1999), como qualidade e flexibilidade.

Posteriormente, Franco e Bourne (2003) revelam que em meados de 1990 a literatura focou em desenhos de sistemas de medição de desempenho e os gerentes estavam preocupados em elaborar mapas estratégicos de sucesso e definir quais tipos de indicadores eram ideais para suas empresas.

Várias arquiteturas e modelos de medição de desempenho surgiram, como o SMART - Strategic Measurement and Reporting Technique, a Matriz de Medição de desempenho, Balanced Scorecard (BSC), Sistema de Medição de Desempenho de Cambridge (NUDURUPATI et al., 2011).

Segundo Kaplan e Norton (1997), o Balanced Scorecard é um modelo que integra as medidas derivadas da estratégia, complementando de forma equilibrada as medidas financeiras, que relatam os acontecimentos passados, com as medidas dos vetores, que alavancam os desempenhos futuros.

Os autores argumentam que a estratégia e as medidas de desempenho são organizadas em um sistema de informações tangível a todos os funcionários dos diversos níveis de uma organização, 
para gerenciar melhor ações de curto, médio e longo prazo e atingir o desempenho desejado em longo prazo.

Para Oliveira et al. (2012), o BSC é uma ferramenta de planejamento e gestão para auxiliar as empresas, a qual permite avaliar o desempenho através de indicadores de controle, que mede a relação de suas quatro perspectivas: Financeira, do Cliente, dos Processos internos e da Aprendizagem e crescimento.

No Quadro 1, descreve-se cada perspectiva do Balanced Scorecard:

Percebe-se a existência de uma relação de causa e efeito entre as perspectivas, onde os objetivos de uma são estruturados para oferecer subsídios para alcançar os demais, e assim sucessivamente.

Além disso, as quatro perspectivas não são definitivas, ou seja, dependendo das circunstâncias em que se inserem, outras podem ser agregadas às demais para complementá-las, como explicam Kaplan e Norton (1997).

Kaplan e Norton (1997) explicam que o que diferencia o BSC dos demais sistemas de medição de

\section{Quadro 1}

Perspectivas utilizadas no BSC

\begin{tabular}{|c|l|}
\hline Perspectivas & \multicolumn{1}{|c|}{ Descrição } \\
\hline Financeira & $\begin{array}{l}\text { Tratam de como as açães impactarão sobre o desempenho financeiro da organização, ou seja, se } \\
\text { a implementação e execução da estratégia melhora os resultados financeiros }\end{array}$ \\
\hline Cliente & $\begin{array}{l}\text { Permite que a organização alinhe suas medidas de resultados em relação aos clientes, } \\
\text { basicamente para compreender as suas necessidades }\end{array}$ \\
\hline $\begin{array}{c}\text { Processos } \\
\text { internos }\end{array}$ & $\begin{array}{l}\text { A corporação procura atingir o grau de excelência dos seus processos críticos que venham a } \\
\text { influenciar os resultados das perspectivas financeira e dos clientes }\end{array}$ \\
\hline $\begin{array}{c}\text { Aprendizado } \\
\text { e crescimento }\end{array}$ & $\begin{array}{l}\text { Busca responder o que será necessário em termos de sistemas, infraestrutura e relação entre } \\
\text { funcionários da empresa para atingir os objetivos das demais perspectivas }\end{array}$ \\
\hline
\end{tabular}

Fonte - Adaptado de Kaplan e Norton, 1997.

O diferencial das organizações públicas é que a perspectiva do cliente é a primeira e, posteriormente, a financeira, pois Silva (2009) afirma que, por se tratar de organizações onde o lucro não é a sua principal desempenho é o fato deste se mostrar como um sistema de comunicação, informação e aprendizado que articula a estratégia empresarial, comunicando a missão e a estratégia e ajudando a alinhar iniciativas para alcançarem um objetivo comum

Mesmo sendo concebida objetivando o lucro, os criadores do BSC, Kaplan e Norton (2001, apud SILVA, 2009) concordam que o BSC pode ser importante para o auxílio da administração pública, sem fins lucrativos. Pelas características desse tipo de organização ser muito particular, a hierarquia das suas perspectivas é diferente das organizações lucrativas (em ordem hierárquica: financeira; dos clientes; dos processos internos; e do aprendizado e crescimento). 
Para a implantação do BSC, independentemente do tipo de organização, é preciso que seja definido claramente qual a missão, a visão e os objetivos estratégicos da organização.

Trata-se de uma condição fundamental, pois a partir desses elementos serão definidos os indicadores que mostrarão o alcance das estratégias (CISLAGHI; LUZ FILHO, 2006).

Além disso, é importante se adequar aos novos propósitos por meio da revisão dos processos existentes e criar um mapa estratégico, que descreve e comunica a estratégia de maneira clara (KAPLAN; NORTON, 1997).

Cislaghi e Luz Filho (2006) explicam que uma instituição de ensino superior (IES) se trata de uma organização social de prestação de serviços e deve ter uma missão definida que oriente sua atuação junto à sociedade, como qualquer organização. Dessa forma, pode-se concluir que qualquer IES pode utilizar ferramentas para acompanhar sua gestão, inclusive o BSC.

Yorke apud Olszak (2012) diz que, a medição da eficácia de uma universidade teve que ser realizada em dois níveis. O primeiro deve focalizar as relações que as universidades mantem com seu ambiente externo. O segundo deve destacar a eficácia das suas operações interiores. Portanto, faz-se necessário uma análise do ambiente interno e externo de uma universidade.

Meyer apud Lima (2003) cita que as universidades públicas de forma geral são muito influenciadas burocraticamente, possuem baixa produtividade, dependência do Estado, resistência a mudanças. Além disso, por se tratarem de organizações sem fins lucrativos, onde os gastos são limitados às rubricas orçamentárias, as universidades devem decidir onde e como aplicar suas disponibilidades financeiras baseando-se em suas prioridades.
Lima (2003) em seu estudo sobre a proposição de um BSC para gestão estratégica das Universidades Fundacionais Catarinenses (UFC'S) explicou que são relevantes, e devem ser considerados os seguintes aspectos: "a busca de uma gestão estratégica que vise aumentar sua competitividade e produtividade, fornecer aos seus clientes, funcionários, alunos, empregadores e comunidade serviços que atendam às várias funções pertinentes (ensino, pesquisa e extensão)".

Cislaghi e Luz Filho (2006) em seu trabalho sobre "Balanced Scorecard em Instituições Públicas do Ensino Superior" sintetizam diversas publicações, onde em muitas são inseridas perspectivas para complementar cada contexto em questão. Alguns exemplos de perspectivas inseridas em organizações públicas de ensino: perspectiva da educação; da responsabilidade financeira; social; do doador; do beneficiário; dos acionistas, entre outras.

Diante desse contexto, a escolha da ferramenta BSC para tal estudo é fundamentada na sua metodologia de implementar a estratégia, utilizada cada vez mais por empresas de diversos setores e também em organizações não governamentais e de caráter educacional.

\subsection{INDICADORES DE SUSTENTABILIDADE}

A noção de ter indicadores de sustentabilidade vem crescendo na medida em que aspectos econômicos, sociais e ambientais vem ganhando força nas organizações.

Veleva e Ellenbecker (2001) colocam que os indicadores de sustentabilidade têm como objetivos:

- Educar o negócio sobre sustentabilidade;

- Informar a tomada de decisão fornecendo informações concisas sobre o estado atual e tendências sobre o desempenho da empresa ou instalações; 
- Promover o aprendizado organizacional;

- Fornecer à organização com a ferramenta para medir seus objetivos rumo à objetivos e metas para processos sustentáveis;

- Permitir a comparação entre empresas acerca do desempenho e nos aspectos ambientais sociais e econômicos da produção;

- Fornecer uma ferramenta para encorajar o envolvimento de stakeholders na tomada de decisão.

Observa-se que os indicadores de sustentabilidade servem como ferramentas de benchmarking, ferramenta de gestão e envolver os stakeholders na organização.

Apesar de ter objetivos definidos, de acordo com Hubbard (2009) a dificuldade e complexidade em medir o desempenho organizacional das empresas com relação à sustentabilidade levam à exigência de um modelo de medição de desempenho eficiente, agradável e simples que leve em consideração as vertentes econômica, social e ambiental.

Diante disso, diversas abordagens para medir 0 desempenho em termos de sustentabilidade, apontando para o desenvolvimento de diversos indicadores, tais como o Índice Dow Jones de Sustentabilidade e o ranking KLD, normas de gestão como a ISO 26000 e OHSAS 18000, e o próprio uso adaptado do Balanced Scorecard (ANTOLÍN-LOPEZ; DELGADO-CEBALLOS; MONTIE, 2016).

Mesmo com tais iniciativas, Oliveira et al. (2012) comentam que há dificuldades em relacionar a sustentabilidade com o planejamento estratégico da organização, principalmente com o BSC, e que a relação da sustentabilidade com 0 planejamento estratégico das empresas não está bem definido.

Hallstedt, Ny e Robe (2010) sugerem que para ser efetiva, a sustentabilidade deve estar ligada aos objetivos organizacionais, incentivos internos e sistemas de avaliação e sistemas de suporte à decisão.
Logo, o comprometimento de longo prazo deve ser evidente no planejamento estratégico, permeando todos os níveis organizacionais.

\section{Metodologia}

A pesquisa teve como objeto de estudo o campus de uma universidade pública no interior do estado do Pará. O campus relatado é o mais novo de 20 campi do estado. A escolha ocorreu por conta de o mesmo apresentar algumas ferramentas de gestão já implantadas, como controle de estoque, quantitativo de alunos em cada turma, além de outros controles de processos que facilitam a implantação de indicadores de sustentabilidade. $\mathrm{O}$ estudo focou em desenvolver indicadores de sustentabilidade para a gestão administrativa do campus.

O campus está ligado hierarquicamente diretamente à reitoria da universidade, porém possui autonomia para o desenvolvimento de atividades de gestão que facilitem a administração do mesmo. Vale ressaltar que os resultados obtidos com essa pesquisa estão aliados aos princípios da instituição superior.

O método de pesquisa empregado foi a pesquisa-ação que, segundo Martins, Mello e Turrioni (2013), cada vez é utilizado como método de pesquisa na área Engenharia de Produção, pois a permite a mudança de determinada realidade para resolver um problema e colaborar para a base do conhecimento, independente da ação ser de sucesso ou não. Dessa forma, com caráter qualitativo, o estudo foi efetivado seguindo as etapas:

1. Confirmação dos valores, missão e visão e análise dos pontos fortes e fracos do ambiente interno e das oportunidades e ameaças do ambiente externo da universidade e do campus: para obtenção dos dados, foram feitas entrevistas com a coordenadora geral; coordenadora administrativa e engenheira de produção do campus, dentre outros funcionários, além 
de obtenção da análise de documentos públicos da universidade que possuem estas informações;

2. Análise das forças e fraquezas, oportunidades e ameaças do campus: foi aplicado junto a encarregados a alta administração do campus, um questionário qualitativo com perguntas baseadas identificando as forças, fraquezas, oportunidades e ameaças, para obter as diferentes visões dos envolvidos nos setores. Para isso, foi preciso fazer uma pequena palestra sobre os conceitos pertinentes e transmitir a missão e visão para os resultados estarem alinhados com estes;

3. Desenvolvimento do mapa estratégico preliminar: procedeu-se a análise crítica do mapa estratégico desenvolvido e o levantamento dos objetivos e ações que deveriam ser desencadeados para que a Instituição conseguisse cumprir a missão e os objetivos a que se propõe;

4. Refinamento do mapa estratégico do campus: estabeleceu-se quais perspectivas do BSC seriam utilizadas, de acordo com a realidade interna e externa do campus. Para tanto, foram realizadas reuniões com a alta administração para determinar os objetivos do mapa estratégico de acordo com as perspectivas e a análise interna e externa, anteriormente definidas. Após isso, foi preciso interrelacionar os objetivos determinados para construir 0 mapa estratégico;

5. Desenvolvimento e implementação do plano de ação do campus: foi necessário converter os objetivos em medidas, métricas, alvos e iniciativas. Por meio de consenso com a coordenação do campus e os funcionários, para então ser definido o plano e implementado utilizando planilhas eletrônicas para preenchimento e controle de informações para a avaliação do alcance dos objetivos.

\section{Resultados e Discussões}

Conforme abordado na seção 3, o início da pesquisa deu-se pela avaliação da missão e visão do campus. Verificou-se que as mesmas já estavam definidas pela própria instituição, portanto foi preciso apenas conhecê-las. Segue abaixo suas respectivas definições:

Missão: Atuar de forma eficiente visando à satisfação das necessidades de capital intelectual e humano da região, proporcionando ensino, pesquisa e extensão de qualidade por meio da ética e responsabilidade socioambiental.

Visão: Ser referência como centro polarizador de tecnologia no desenvolvimento de conhecimento científico e inovação tecnológica no estado do Pará.

Com base nessas informações, foi construída a matriz SWOT do campus. Foram associadas à matriz as respostas anteriormente existentes do diagnóstico organizacional geral da instituição, onde foram selecionadas apenas as que se aplicavam ao campus, juntamente com o questionário qualitativo aplicado. A ampliação do SWOT considerando questões inerentes ao campus foi feita com a finalidade de incluir a realidade local do munícipio e as particularidades do campus.

No Quadro 2 a Matriz SWOT parcialmente elaborada (para não comprometer a instituição), no qual os elementos em azul são procedentes do diagnóstico geral e os em laranja são procedentes das respostas do questionário realizado: 
Quadro 2

Matriz SWOT do Campus XX da Universidade

\begin{tabular}{|c|c|c|}
\hline & $\begin{array}{l}\text { FORÇAS } \\
\text { (Strengths) }\end{array}$ & FRAQUEZAS (Weaknesses) \\
\hline \multirow{12}{*}{ 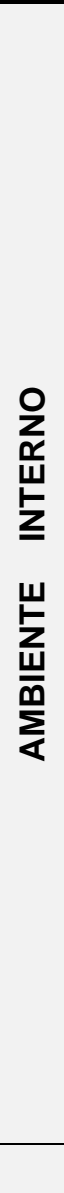 } & $\begin{array}{l}\text { Habilidades essenciais para cumprimento da } \\
\text { missão }\end{array}$ & $\begin{array}{l}\text { Definição inadequada de competências de setores, } \\
\text { cargos e funções na universidade; }\end{array}$ \\
\hline & $\begin{array}{l}\text { Reconhecimento institucional no âmbito da } \\
\text { sociedade; }\end{array}$ & $\begin{array}{l}\text { Ausência de um sistema Informatizado que integre as } \\
\text { ações da gestão; }\end{array}$ \\
\hline & Alta capilaridade e abrangência em suas ações & Fragilidade no processo de avaliação institucional \\
\hline & $\begin{array}{l}\text { Realização de ações com impacto positivo sobre } \\
\text { o desenvolvimento regional; }\end{array}$ & $\begin{array}{l}\text { Insuficiência e inadequações na infraestrutura para o } \\
\text { desenvolvimento das ações de ensino, pesquisa, } \\
\text { extensão e gestão }\end{array}$ \\
\hline & Fluxo de informações facilitado aos alunos; & $\begin{array}{l}\text { Políticas insuficientes e/ou inadequadas para a } \\
\text { permanência de servidores qualificados na universidade }\end{array}$ \\
\hline & $\begin{array}{l}\text { Bom gerenciamento para aplicação dos recursos } \\
\text { financeiros às prioridades imediatas; }\end{array}$ & $\begin{array}{l}\text { Mecanismos de acompanhamento e controle ineficientes } \\
\text { na execução das ações de gestão administrativa e } \\
\text { acadêmica. }\end{array}$ \\
\hline & $\begin{array}{l}\text { Boa relação entre os funcionários e prestadores } \\
\text { de serviços; }\end{array}$ & Materiais de limpeza limitados (empresa terceirizada); \\
\hline & $\begin{array}{l}\text { Boa infraestrutura do campus em geral (salas } \\
\text { amplas e climatizadas, rampa de acesso, } \\
\text { estacionamento para funcionários, quadras de } \\
\text { esporte); }\end{array}$ & Escassez de treinamento para funcionários; \\
\hline & $\begin{array}{l}\text { Oferta de estágios, projetos, monitoria e } \\
\text { pesquisa e extensão aos alunos; }\end{array}$ & $\begin{array}{l}\text { Desconhecimento da destinação correta de materiais } \\
\text { recicláveis e bens inservíveis; }\end{array}$ \\
\hline & $\begin{array}{l}\text { Fácil acessibilidade dos alunos aos laboratórios } \\
\text { de informática, física e química; }\end{array}$ & Baixa oferta de mini cursos aos alunos; \\
\hline & Parceria com órgãos públicos e privados. & Pouco contato com a comunidade local. \\
\hline & OPORTUNIDADES (Opportunities) & AMEAÇAS (Threats) \\
\hline \multirow{8}{*}{ 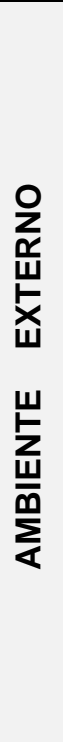 } & Disponibilidade de editais de fomento; & Incerteza na execução fiscal do Estado; \\
\hline & $\begin{array}{l}\text { Ambiente institucional favorável a formalização } \\
\text { de parcerias entre universidades, centros de } \\
\text { pesquisa, fundações, instituições de pesquisa, } \\
\text { empresas privadas, etc.; }\end{array}$ & Limitações Orçamentárias; \\
\hline & $\begin{array}{l}\text { Existência de demanda para a realização de } \\
\text { concurso público; }\end{array}$ & Poucas Políticas públicas que priorizem a universidade; \\
\hline & $\begin{array}{l}\text { Demanda por formação profissional nas áreas } \\
\text { voltadas para os programas de desenvolvimento } \\
\text { do Estado; }\end{array}$ & $\begin{array}{l}\text { Carência de profissionais qualificados em determinadas } \\
\text { regiões do Estado para integrar o quadro permanente da } \\
\text { universidade; }\end{array}$ \\
\hline & $\begin{array}{l}\text { Existência de grandes projetos que estão em } \\
\text { desenvolvimento no Estado; }\end{array}$ & Lei de licitação; \\
\hline & $\begin{array}{l}\text { Crescimento da cidade onde se localiza o } \\
\text { campus; }\end{array}$ & Localização afastada do campus; \\
\hline & Captação de recursos de empresas locais; & Mudança do Governo do Estado; \\
\hline & Adequação ao "plano de resíduos sólidos". & Segurança precária nos arredores do campus. \\
\hline
\end{tabular}

Fonte - Próprio autor. 
Considerando os componentes da matriz SWOT e a missão e visão da universidade, foram criados os objetivos para construir o mapa estratégico do campus para um horizonte de tempo de dois anos.

Escolheu-se manter as perspectivas tradicionais do BSC e complementá-las com a perspectiva da inovação, que se trata das inovações existentes no âmbito educacional que incentivem o ensino, a pesquisa e extensão. Além disso, a perspectiva do cliente sofreu uma alteração sendo complementada pela visão do beneficiário, já que o cliente direto de uma IES é o discente, porém existem beneficiários que não usufruem dos serviços educacionais diretos oferecidos pela universidade, como a comunidade local, empresas e a sociedade em geral. Para manter a proposta do tripé da sustentabilidade, as vertentes ambiental e social foram abordadas dentro dos objetivos.
Essas mudanças nas perspectivas são comuns em estudos de medição de desempenho em sustentabilidade. Valenzuela e Maturana (2016) incluem perspectivas ambiental e outra social, que tem como finalidade a inserção de objetivos que atendam à stakeholders externos.

Lima (2003) adotou perspectivas bem diferentes ao abordar as perspectivas de funções acadêmicas, processos de geração de valor, desenvolvimento e crescimento profissional e gestão econômicofinanceira, sendo esta última a base para as outras perspectivas.

Essa diferença justifica-se também pelo fato de a pesquisa de Lima (2003) se aplicada em toda a universidade, enquanto que a pesquisa em questão está focada em um campus universitário.

Na Figura 1, o mapa estratégico elaborado:

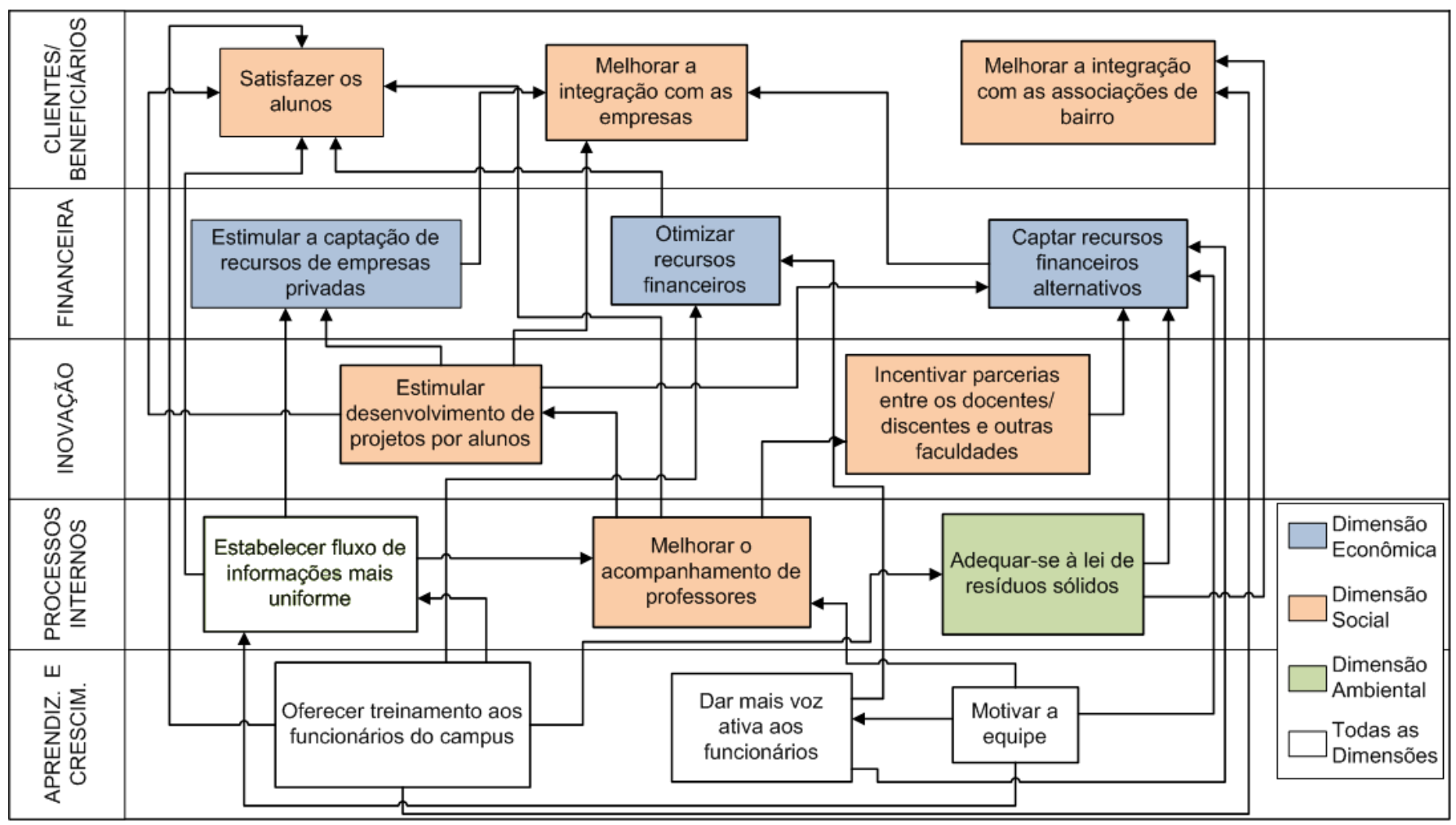

Figura 1 - Mapa estratégico do Campus XX da Universidade. Fonte - Próprio autor.

As perspectivas do mapa foram organizadas hierarquicamente, onde os objetivos das perspectivas de baixo procuram dar base para atender os objetivos mais acima, obedecendo à relação de causa e efeito. 
Por exemplo, na perspectiva do aprendizado e crescimento, o objetivo "oferecer treinamento aos funcionários do campus" busca alicerçar os objetivos "estabelecer fluxo de informações mais uniforme", "adequar-se à lei de resíduos sólidos", "satisfazer os alunos" e "melhorar a integração com as associações de bairro". O objetivo "dar mais voz ativa aos funcionários" procura concretizar os objetivos "otimizar recursos financeiros" e "captar recursos financeiros alternativos". O objetivo "motivar a equipe" busca atingir os objetivos "oferecer treinamento aos funcionários do campus", "dar mais voz ativa aos funcionários", "melhorar o acompanhamento de professores" e "captar recursos financeiros alternativos".

Outro exemplo é quanto à perspectiva financeira, que apresenta os objetivos "estimular a captação de recursos de empresas privadas" e "captar recursos financeiros alternativos", que procuram concretizar 0 objetivo "melhorar a integração com as empresas". E também o objetivo "otimizar recursos financeiros", que busca dar base para o objetivo "satisfazer os alunos". Os objetivos da perspectiva dos clientes/beneficiários não expõem relação de causa e efeito entre eles.

O mapa ainda demonstra à qual dimensão do tripé da sustentabilidade cada objetivo está pautado: os objetivos $\urcorner$ "satisfazer os alunos", "melhorar a integração com as empresas", "melhorar a integração com as associações de bairro", "estimular desenvolvimento de projetos por alunos", "incentivar parcerias entres os docentes/discentes e outras faculdades" e "melhorar o acompanhamento de professores" estão voltados para a dimensão social, logo está destacado em laranja, como explica a legenda. Os objetivos "estimular a captação de recursos de empresas privadas", "otimizar recursos financeiros" e "captar recursos financeiros alternativos", destacados de azul, estão interligados à dimensão econômica. O objetivo "adequar-se à lei de resíduos sólidos" está relacionado à dimensão ambiental, logo está pintado de verde. Foi definido apenas um objetivo voltado para essa dimensão devido à falta de conhecimento suficiente relacionada à esta questão. Já os objetivos "estabelecer fluxo de informações mais uniforme", "oferecer treinamentos aos funcionários do campus", "dar mais voz ativa aos funcionários" e "motivar a equipe" estão interligados à todas as dimensões.

No que tange à escolha dos objetivos estratégicos, Fallen et al. (2016) também utiliza o objetivo estratégico de satisfazer consumidores, mesmo em um estudo de medição de desempenho voltado para sustentabilidade.

Lima (2003) enfatiza também em seus objetivos a importância de integração com a comunidade externa ao citar o objetivo "ser bom cidadão corporativo".

No que tange à perspectiva financeira, Lima (2003) também possui um objetivo semelhante chamado de "melhorar a estrutura de custos" e "racionalização e normatização de processos". Fallen et al. (2016) também traz um objetivo chamado "eficiência e eficácia de custos".

Valenzuela e Maturana (2016) e Fallen et al. (2016) também enfatizam a importância de ter objetivos estratégicos voltados para o funcionário, como qualificação do funcionário, satisfação do funcionário.

Valenzuela e Maturana (2016) trata de um objetivo semelhante a "dar mais voz ativa aos funcionários" e "motivar equipe" ao mencionar o objetivo estratégico "dar mais empowerment aos funcionários".

Os objetivos estratégicos desenvolvidos nesta pesquisa acabam por serem bem diferentes do que os encontrados na literatura em virtude do próprio escopo reduzido de um campus universitário, uma vez que Valenzuela e Maturana (2016) tratam da indústria de vinho e Fallen et al. (2016) trata de uma pequena empresa, enquanto Lima (2003), conforme tratado 
anteriormente aborda uma universidade com todos os campi.

A partir do mapa, foi desenvolvido o plano de ação do campus, contendo medidas, métricas, alvos e iniciativas.

A escolha das medidas (indicadores) foi baseada nas iniciativas propostas para alcançar os objetivos do mapa estratégico, orientando de que forma será avaliado o progresso até alcançar os objetivos. Cada indicador contém métricas para traduzi-las para a forma quantificada.
Os alvos estabelecidos foram elaborados de maneira qualitativa junto à coordenação do campus para um horizonte de no máximo dois anos, medido em nível e porcentagem de melhoria em relação ao estado inicial de cada indicador. $O$ tripé da sustentabilidade também pode ser observado dentro das iniciativas, onde foram sugeridas ações de cunho econômico e socioambiental.

Nos Quadros 3, 4, 5, 6 e 7 apresenta-se o plano de ação elaborado com base em cada perspectiva:

Quadro 3

Plano de ação segundo a perspectiva do cliente/beneficiário.

\begin{tabular}{|c|c|c|c|c|c|c|}
\hline \multirow[b]{2}{*}{ Objetivo } & \multirow[b]{2}{*}{ Medida } & \multirow[b]{2}{*}{ Métrica } & \multicolumn{3}{|c|}{ Alvos } & \multirow[b]{2}{*}{ Iniciativas } \\
\hline & & & $\begin{array}{c}6 \\
\text { meses }\end{array}$ & $\begin{array}{c}1 \\
\text { ano }\end{array}$ & $\begin{array}{c}2 \\
\text { anos }\end{array}$ & \\
\hline \multirow{3}{*}{$\begin{array}{l}\text { Satisfazer os } \\
\text { alunos }\end{array}$} & \multirow{2}{*}{$\begin{array}{l}\text { Aumento do } \\
\text { interesse dos } \\
\text { alunos }\end{array}$} & $\begin{array}{c}\text { Taxa de } \\
\text { presença dos } \\
\text { alunos às aulas }\end{array}$ & $25 \%$ & $50 \%$ & $75 \%$ & \multirow{3}{*}{$\begin{array}{l}\text { Promover cursos de extensão; } \\
\text { Estruturação dos laboratórios. }\end{array}$} \\
\hline & & $\begin{array}{c}\text { Número de } \\
\text { estudantes } \\
\text { desistentes dos } \\
\text { cursos }\end{array}$ & $30 \%$ & $20 \%$ & $15 \%$ & \\
\hline & $\begin{array}{l}\text { Percepção dos } \\
\text { alunos }\end{array}$ & $\begin{array}{c}\text { Nível de } \\
\text { satisfação do } \\
\text { aluno }\end{array}$ & $50 \%$ & $75 \%$ & $90 \%$ & \\
\hline \multirow{2}{*}{$\begin{array}{c}\text { Melhorar a } \\
\text { integração } \\
\text { com as } \\
\text { empresas }\end{array}$} & $\begin{array}{c}\text { Aumento de } \\
\text { empresas } \\
\text { parceiras }\end{array}$ & $\begin{array}{c}\text { Número de } \\
\text { empresas } \\
\text { parceiras }\end{array}$ & $10 \%$ & $20 \%$ & $40 \%$ & \multirow{2}{*}{$\begin{array}{l}\text { Promover encontro com os } \\
\text { representantes das empresas a fim de } \\
\text { verificar quais profissionais demandam; } \\
\text { oferecer cursos que atendam às } \\
\text { necessidades da região. }\end{array}$} \\
\hline & $\begin{array}{c}\text { Melhoria do } \\
\text { bem-estar das } \\
\text { empresas }\end{array}$ & $\begin{array}{c}\text { Nível de } \\
\text { satisfação das } \\
\text { empresas } \\
\text { parceiras }\end{array}$ & $50 \%$ & $70 \%$ & $85 \%$ & \\
\hline $\begin{array}{c}\text { Melhorar a } \\
\text { integração } \\
\text { com as } \\
\text { associações } \\
\text { de bairro }\end{array}$ & $\begin{array}{l}\text { Criação de } \\
\text { projetos } \\
\text { comunitários }\end{array}$ & $\begin{array}{c}\text { Número de } \\
\text { novas ações e } \\
\text { projetos } \\
\text { direcionados à } \\
\text { comunidade }\end{array}$ & $20 \%$ & $30 \%$ & $40 \%$ & $\begin{array}{c}\text { Desenvolver projetos que envolvam a } \\
\text { comunidade; oferecer cursos rápidos; } \\
\text { promover palestras (apresentação dos } \\
\text { cursos, educação ambiental, práticas de } \\
\text { empreendedorismo, saúde pública, } \\
\text { políticas públicas), para trazer o } \\
\text { envolvimento com outras entidades; } \\
\text { promover cursos de reciclagem. }\end{array}$ \\
\hline
\end{tabular}

Fonte - Próprio autor. 
Quadro 4

Plano de ação segundo a perspectiva financeira.

\begin{tabular}{|c|c|c|c|c|c|c|}
\hline \multirow[b]{2}{*}{ Objetivo } & \multirow[b]{2}{*}{ Medida } & \multirow[b]{2}{*}{ Métrica } & \multicolumn{3}{|c|}{ Alvos } & \multirow[b]{2}{*}{ Iniciativas } \\
\hline & & & $\begin{array}{c}6 \\
\text { meses }\end{array}$ & $\begin{array}{c}1 \\
\text { ano }\end{array}$ & $\begin{array}{c}2 \\
\text { anos }\end{array}$ & \\
\hline $\begin{array}{c}\text { Otimizar } \\
\text { recursos } \\
\text { financeiros }\end{array}$ & $\begin{array}{l}\text { Economia } \\
\text { de gastos }\end{array}$ & $\begin{array}{l}\% \text { de } \\
\text { redução de } \\
\text { custos }\end{array}$ & $10 \%$ & $25 \%$ & $40 \%$ & $\begin{array}{l}\text { Rever os processos para verificar onde reduzir } \\
\text { gastos; envolver os funcionários para reduzirem } \\
\text { gastos e retrabalhos em seus setores. }\end{array}$ \\
\hline $\begin{array}{l}\text { Estimular a } \\
\text { captação de } \\
\text { recursos de } \\
\text { empresas } \\
\text { privadas }\end{array}$ & \multirow{2}{*}{$\begin{array}{l}\text { Aumento } \\
\text { de } \\
\text { recursos } \\
\text { captados }\end{array}$} & $\begin{array}{l}\text { Valor } \\
\text { proveniente } \\
\text { da } \\
\text { captação } \\
\text { de recursos }\end{array}$ & $30 \%$ & $50 \%$ & $70 \%$ & $\begin{array}{l}\text { Buscar financiamentos junto as empresas, para } \\
\text { desenvolvimento de produtos e projetos de seu } \\
\text { interesse. }\end{array}$ \\
\hline $\begin{array}{l}\text { Captar } \\
\text { recursos } \\
\text { financeiros } \\
\text { alternativos }\end{array}$ & & $\begin{array}{l}\text { Valor } \\
\text { proveniente } \\
\text { das fontes } \\
\text { alternativas } \\
\text { de receita }\end{array}$ & $30 \%$ & $50 \%$ & $70 \%$ & $\begin{array}{l}\text { Venda de materiais reciclados; Bazar de objetos } \\
\text { usados; Promoção de eventos esportivos; } \\
\text { Promoção de cursos para a comunidade } \\
\text { acadêmica e externa. }\end{array}$ \\
\hline
\end{tabular}

Fonte - Próprio autor.

Quadro 5

Plano de ação segundo a perspectiva da inovação.

\begin{tabular}{|c|c|c|c|c|c|c|}
\hline \multirow[b]{2}{*}{ Objetivo } & \multirow[b]{2}{*}{ Medida } & \multirow[b]{2}{*}{ Métrica } & \multicolumn{3}{|c|}{ Alvos } & \multirow[b]{2}{*}{ Iniciativas } \\
\hline & & & $\begin{array}{c}6 \\
\text { meses }\end{array}$ & $\begin{array}{c}1 \\
\text { ano }\end{array}$ & $\begin{array}{c}2 \\
\text { anos }\end{array}$ & \\
\hline \multirow{2}{*}{$\begin{array}{c}\text { Estimular } \\
\text { desenvolvimento } \\
\text { de projetos por } \\
\text { alunos }\end{array}$} & $\begin{array}{l}\text { Incentivo de } \\
\text { projetos }\end{array}$ & $\begin{array}{l}\text { Número de } \\
\text { professores } \\
\text { que associam o } \\
\text { desenvolviment } \\
\text { o de projetos } \\
\text { às matérias } \\
\text { lecionadas }\end{array}$ & $25 \%$ & $35 \%$ & $40 \%$ & \multirow{2}{*}{$\begin{array}{c}\text { Realizar debates com professores } \\
\text { para levantar quais modalidades de } \\
\text { projetos teriam relevância para a } \\
\text { sociedade; buscar, utilizando a ótica } \\
\text { do aluno as ideias para elaboração } \\
\text { de projetos; incentivar as pesquisas } \\
\text { de campo para ver as reais } \\
\text { necessidades da comunidade } \\
\text { envolvida; propor oficinas, para os } \\
\text { alunos praticarem seus } \\
\text { conhecimentos. }\end{array}$} \\
\hline & $\begin{array}{l}\text { Publicação de } \\
\text { artigos }\end{array}$ & $\begin{array}{l}\text { Número de } \\
\text { novos artigos } \\
\text { publicados }\end{array}$ & $30 \%$ & $40 \%$ & $50 \%$ & \\
\hline $\begin{array}{c}\text { Incentivar } \\
\text { parcerias entre } \\
\text { os } \\
\text { docentes/discent } \\
\text { es e outras } \\
\text { faculdades }\end{array}$ & $\begin{array}{l}\text { Aumento de } \\
\text { parcerias } \\
\text { Interinstitucio } \\
\text { nais }\end{array}$ & $\begin{array}{l}\text { Número de } \\
\text { parcerias } \\
\text { realizadas }\end{array}$ & $20 \%$ & $30 \%$ & $50 \%$ & $\begin{array}{c}\text { Organizar } \\
\text { palestras/debates/semana de } \\
\text { integração com a participação de } \\
\text { docentes e discentes de outras } \\
\text { universidades. }\end{array}$ \\
\hline
\end{tabular}

Fonte - Próprio autor. 
Quadro 6

Plano de ação segundo a perspectiva dos processos internos.

\begin{tabular}{|c|c|c|c|c|c|c|}
\hline \multirow[b]{2}{*}{ Objetivo } & \multirow[b]{2}{*}{ Medida } & \multirow[b]{2}{*}{ Métrica } & \multicolumn{3}{|c|}{ Alvos } & \multirow[b]{2}{*}{ Iniciativas } \\
\hline & & & $\begin{array}{c}6 \\
\text { meses }\end{array}$ & $\begin{array}{c}1 \\
\text { ano }\end{array}$ & $\begin{array}{c}2 \\
\text { anos }\end{array}$ & \\
\hline $\begin{array}{l}\text { Estabelecer } \\
\text { fluxo de } \\
\text { informações } \\
\text { mais uniforme }\end{array}$ & $\begin{array}{l}\text { Comunicação } \\
\text { eficiente }\end{array}$ & $\begin{array}{l}\text { Índice de avaliação } \\
\text { dos funcionários } \\
\text { quanto à } \\
\text { comunicação do } \\
\text { campus }\end{array}$ & $30 \%$ & $20 \%$ & $15 \%$ & $\begin{array}{l}\text { Implantar mecanismos que amplie } \\
\text { a disseminação da informação } \\
\text { (quadros informativos). }\end{array}$ \\
\hline \multirow{2}{*}{$\begin{array}{l}\text { Melhorar o } \\
\text { acompanhament } \\
\text { o de professores }\end{array}$} & $\begin{array}{l}\text { Conformidade } \\
\text { eficiente dos } \\
\text { docentes }\end{array}$ & $\begin{array}{c}\text { Nível de } \\
\text { cumprimento da } \\
\text { matriz curricular da } \\
\text { matéria lecionada }\end{array}$ & $75 \%$ & $85 \%$ & $90 \%$ & \multirow{2}{*}{$\begin{array}{c}\text { Estabelecer planilhas de } \\
\text { acompanhamento, em que o } \\
\text { professor possa inserir as } \\
\text { informações sobre as atividades a } \\
\text { serem realizada com as turmas. }\end{array}$} \\
\hline & $\begin{array}{l}\text { Cobrança de } \\
\text { assiduidade } \\
\text { dos docentes }\end{array}$ & $\begin{array}{c}\% \text { de presença dos } \\
\text { docentes }\end{array}$ & $75 \%$ & $85 \%$ & $90 \%$ & \\
\hline $\begin{array}{l}\text { Adequar-se à lei } \\
\text { de resíduos } \\
\text { sólidos }\end{array}$ & $\begin{array}{c}\text { Destinação } \\
\text { dos resíduos }\end{array}$ & $\begin{array}{l}\text { Quantidade de } \\
\text { resíduos } \\
\text { destinados } \\
\text { corretamente }\end{array}$ & $60 \%$ & $70 \%$ & $80 \%$ & $\begin{array}{l}\text { Promover palestras de educação } \\
\text { ambiental; implantar coleta } \\
\text { seletiva; incentivar as práticas de } \\
\text { reciclagem. }\end{array}$ \\
\hline
\end{tabular}

Fonte - Próprio autor.

Quadro 7

Plano de ação segundo a perspectiva do aprendizado e crescimento.

\begin{tabular}{|c|c|c|c|c|c|c|}
\hline \multirow[b]{2}{*}{ Objetivo } & \multirow[b]{2}{*}{ Medida } & \multirow[b]{2}{*}{ Métrica } & \multicolumn{3}{|c|}{ Alvos } & \multirow[b]{2}{*}{ Iniciativas } \\
\hline & & & $\begin{array}{c}6 \\
\text { meses }\end{array}$ & $\begin{array}{c}1 \\
\text { ano }\end{array}$ & $\begin{array}{c}2 \\
\text { anos }\end{array}$ & \\
\hline $\begin{array}{c}\text { Oferecer } \\
\text { treinamento aos } \\
\text { funcionários do } \\
\text { campus }\end{array}$ & $\begin{array}{l}\text { Capacitação } \\
\text { e treinamento }\end{array}$ & $\begin{array}{l}\text { Número de } \\
\text { treinamentos } \\
\text { realizados }\end{array}$ & $20 \%$ & $30 \%$ & $40 \%$ & $\begin{array}{l}\text { Oferecer cursos de capacitação; } \\
\text { incentivar a busca por } \\
\text { aperfeiçoamento profissional. }\end{array}$ \\
\hline $\begin{array}{l}\text { Dar mais voz } \\
\text { ativa aos } \\
\text { funcionários }\end{array}$ & $\begin{array}{l}\text { Aceitação de } \\
\text { ideias }\end{array}$ & $\begin{array}{l}\text { Número de novas } \\
\text { ideias sugeridas } \\
\text { pelos funcionários } \\
\text { que foram } \\
\text { acatadas }\end{array}$ & $20 \%$ & $30 \%$ & $40 \%$ & $\begin{array}{c}\text { Dar abertura para o desenvolvimento } \\
\text { da criatividade. }\end{array}$ \\
\hline $\begin{array}{l}\text { Motivar a } \\
\text { equipe }\end{array}$ & $\begin{array}{l}\text { Cooperação e } \\
\text { envolvimento } \\
\text { da equipe }\end{array}$ & $\begin{array}{l}\text { Índice de } \\
\text { eficiência na } \\
\text { execução dos } \\
\text { serviços }\end{array}$ & $50 \%$ & $75 \%$ & $80 \%$ & $\begin{array}{l}\text { Avaliar melhor as habilidades dos } \\
\text { funcionários. }\end{array}$ \\
\hline
\end{tabular}

Fonte - Próprio autor. 
A partir dos planos de ação elaborados, a coordenação do campus assumiu o compromisso de implementação das medidas, alvos e iniciativas explicitados nos quadros supracitados. Acordou-se também entre os pesquisadores e a coordenação que os indicadores, junto com o mapa estratégico e os planos de ação seriam revistas de 6 em 6 meses para ajustes e complementações.

Para a implementação, decidiu-se que, pelo pequeno tamanho do campus (com 40 funcionários e 600 alunos), os indicadores seriam monitorados utilizando planilhas eletrônicas para gerar uma cultura de controle e monitoramento estratégico e posteriormente seria analisada a possibilidade de inserção de um sistema estruturado de gestão que incluísse os indicadores, mapa e alvos.

\section{ConsideraçõEs FinaIS}

Por meio do planejamento, avaliações, observações e entrevistas, foi possível a criação do mapa estratégico e os planos de ação abordando as perspectivas do Balanced Scorecard, além da criação dos indicadores de desempenho organizacional para a universidade.

A análise do ambiente interno e externo da instituição, por meio da matriz SWOT, deu subsídios para a construção do mapa estratégico e posteriormente, um plano de ação condizente com a missão e visão, estabelecendo indicadores (medidas) para implementar a estratégia do campus universitário.

Os resultados obtidos por meio da pesquisa realizada são bastante relevantes para mostrar o quanto métodos e ferramentas de gestão podem contribuir para ambientes de empresas sem fins lucrativos, especialmente as do setor público, que tanto demandam esforçam para a profissionalização da gestão. A pesquisa também contribui para a extensão do conhecimento acerca de indicadores de sustentabilidade em universidade, necessitando melhores aprofundamentos para que sejam melhor elaborados indicadores ambientais mais pertinentes, principalmente.

Ressalta-se a importância do envolvimento dos funcionários do campus no desenvolvimento do trabalho e no comprometimento da alta gestão superior em replicar os métodos utilizados nesta pesquisa em outros campi, contribuindo para a uniformidade da gestão dentro da universidade.

Entretanto, o trabalho foi limitado quanto à sua implementação, visto que não se dispunha de tempo suficiente para aplicá-lo e analisá-lo.

Sugere-se então para a universidade que tal proposta seja implementada, devendo ser aprimorada de acordo com as transformações percebidas no ambiente no decorrer do tempo, adaptando-a as mudanças e novas necessidades, como exemplo, estruturar métodos quantitativos para uma melhor definição dos alvos, visto que os alvos foram estabelecidos de maneira qualitativa. Além disso, a universidade pode procurar mais embasamento para futuramente desenvolver mais objetivos para o mapa estratégico voltados à dimensão ambiental.

Outra proposta para trabalhos futuros seria a aplicação do BSC sustentável nos demais campus da universidade após constatar os benefícios trazidos ao campus analisado. Dessa forma cada campus poderá implementar suas estratégias especificas alinhadas à estratégia geral da universidade como um todo. 


\section{REFERÊNCIAS}

ANTOLÍN-LOPEZ, R.; DELGADO-CEBALLOS, J.; MONTIEL, I. Deconstructing corporate sustainability: a comparison of different stakeholder metrics. Journal of Cleaner Production, p. 1-13, 2016.

BITITCI, U. S. Managing Business Performance:

The Science and the Art. West Sussex: John Wiley \& Sons Ltd, 2015. v. 53

BITITCI, U. et al. Performance Measurement: Challenges for Tomorrow. International Journal of Management Reviews, v. 14, n. 3, p. 305-327, 2012.

BLACKBURN, W. R. The Sustainability Handbook:

The Complete Management Guide to Achieving Social, Economic and Environmental

Responsibility. 1st ed. Londres: Sterling, 2007.

CISLAGHI, R.; LUZ FILHO, S. S. Balanced Scorecard em Instituições Públicas do Ensino Superior: Benefícios, Limitações e Desafios - In: Colóquio Internacional sobre Gestão Universitária na América do Sul, 6., Blumenau, 2006.

COMISSÃO MUNDIAL SOBRE MEIO AMBIENTE E DESENVOLVIMENTO. Nosso Futuro Comum. 2. ed. Rio de Janeiro: Editora da FGV, 1991.

DYLLICK, T.; HOCKERTS, K. Beyond the business case for corporate sustainability. Business Strategy and the Environment, v. 11, n. 2, p. 130-141, 2002.

ELKINGTON, J. Cannibais de garfo e faca. 1st ed. Makron Books, 2001.

FALLEN, S. et al. Sustainability Management with the Sustainability Balanced Scorecard in SMEs: Findings from an Austrian Case Study. Sustainability, v. 8, n. 545, 2016.

FRANCO, M.; BOURNE, M. Factors that play a role in "managing through measures." Management Decision, v. 41, n. 8, p. 698-710, 2003.

HALLSTEDT, S.; NY, H.; ROBE, K. An approach to assessing sustainability integration in strategic decision systems for product development. Journal of Cleaner Production, v. 18, n. 8, p. 703-712, 2010.

HUBBARD, Graham. Measuring organizational performance: Beyond the triple bottom line, Business Strategy and the Environment, v. 18, p. 177-191, 2009.

KAPLAN, R. S., NORTON, D. P. Tradução de FRAZÃO FILHO, Luiz Euclydes Trindade. A Estratégia em Ação: Balanced Scorecard. 18 ed., Rio de Janeiro:Elsevier, 1997.
LEBAS, M. J. Performance measurement and performance management. International Journal Production Economics, v. 41, n. 1-3, p. 23-35, 1995.

LIMA, M. A. Uma Proposta do Balanced Scorecard para a Gestão Estratégica das Universidades Fundacionais de Santa Catarina. 2003 - Tese (Doutorado em Engenharia de Produção) Universidade Federal de Santa Catarina. Florianópolis, 2003.

MARTINS, R. A. Sistemas de Medição de Desempenho: Um Modelo para Estruturação do Uso. 1999. 269 f - Tese (Doutorado em Engenharia) Escola Politécnica da Universidade de São Paulo, São Paulo. 1999.

MARTINS, R. A.; MELLO, C. H. P.; TURRIONI. J. B. Guia para Elaboração de Monografia e TCC em Engenharia de Produção. São Paulo: Atlas, 2013.

MONTIEL, I.; DELGADO-CEBALLOS, J. Defining and Measuring Corporate Sustainability: Are We There Yet? Organization \& Environment, v. Advance on, p. 1-27, 2014.

NEELY, A.; GREGORY, M.; PLATTS, K. Performance measurement system design: A literature review and research agenda. International Journal of Operations \& Production Management, v. 25, n. 12, p. 1228-1263, 1995.

NUDURUPATI, S. S. et al. State of the art literature review on performance measurement. Computers \& Industrial Engineering, v. 60, n. 2, p. 279-290, 2011.

OLIVEIRA, L. R. et al. Sustentabilidade: da evolução dos conceitos à implementação como estratégia nas organizações. Revista Produção, v. 22, p. 70-82, 2012.

OLSZAK, Eric, Composite indicators for a sustainable campus - Design rationale and methodology: The case of the Catholic Institute of Lille, Ecological Indicators, v. 23, p. $573-577,2012$.

POISTER, T. H.; ARISTIGUETA, M. P.; HALL, J. L. Managing and Measuring Performance in Public and Nonprofit Organizations: An Integrated Approach. 2 ed. Josey-Bass: São Francisco, 2015.

SILVA, L. C. O balanced scorecard e o processo estratégico. Caderno de Pesquisas em

Administração, v. 10, p. 61-73, 2003.

SILVA, R. F. P. B. O Balanced Scorecard Aplicado à Administração Pública: um Modelo Aplicável a 
uma Instituição de Ensino Superior. 2009. 77 f -

Dissertação (Mestrado em Contabilidade) - Faculdade de Economia, Universidade do Porto, Portugal, 2009.

VALENZUELA, L.; MATURANA, S. Designing a threedimensional performance measurement system (SMD3D) for the wine industry: A Chilean example. Agricultural Systems, v. 142, p. 112-121, 2016.
VELEVA, V.; ELLENBECKER, M. Indicators of sustainable production: framework and methodology. Elsevier: Journal of Cleaner Production, Vol.10, p. 520-549, 2001a.

VIANNA, W. B.; ENSSLIN, L. A utilização de ferramentas gerenciais na gestão do terceiro setor: relevância do BSC. Revista Gepros, v. 3, p.61-71, 2007. 